\title{
Cholesterol metabolism in drug-resistant cancer (Review)
}

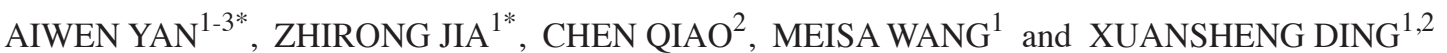 \\ ${ }^{1}$ School of Basic Medicine and Clinical Pharmacy, China Pharmaceutical University; ${ }^{2}$ Precision Medicine Laboratory, \\ School of Basic Medicine and Clinical Pharmacy, China Pharmaceutical University, Nanjing, Jiangsu 211198; \\ ${ }^{3}$ School of Pharmacy, Jiangsu Food and Pharmaceutical Science College, Huaian, Jiangsu 223000, P.R. China
}

Received May 8, 2020; Accepted September 4, 2020

DOI: $10.3892 / \mathrm{ijo} .2020 .5124$

\begin{abstract}
Cancer represents a severe challenge to healthcare systems and individuals worldwide. The development of multiple drug resistance is a major issue regarding cancer therapy, which can result in the progression of disease. Cholesterol is a major constituent of cell membranes and participates in the regulation of several cellular processes, such as cell growth, proliferation, differentiation, survival and apoptosis. Numerous studies have provided correlative support for a role of cholesterol in cancer development and drug resistance. In the present review, recent insights into the regulation of cholesterol metabolism, the association between cholesterol and the efficacy of antitumor agents in preclinical studies, as well as the possible mechanisms through which cholesterol influences drug resistance, are summarized. Furthermore, the clinical relevance of cholesterol to the development of cancer, as well as strategies targeting cholesterol for therapeutic intervention are detailed. Collectively, studies on various types of cancer have suggested that increased cholesterol levels promote resistance to chemotherapeutic drugs in cancer through a variety of mechanisms, and that the depletion of cholesterol using statins significantly enhances the sensitivity of the therapeutic agents. However, additional studies are required to enhance the current understanding of the involvement of cholesterol in the development of drug-resistant cancer.
\end{abstract}

\section{Contents}

1. Introduction

2. Cholesterol metabolism

Correspondence to: Professor Xuansheng Ding, School of Basic Medicine and Clinical Pharmacy, China Pharmaceutical University, 639 Longmian Avenue, Jiangning, Nanjing, Jiangsu 211198, P.R. China

E-mail: DXSCPU@126.com

${ }^{*}$ Contributed equally

Key words: cholesterol, drug resistance, cancer, cholesterol metabolism
3. Role of cholesterol in drug resistance in cancer

4. Mechanisms through which cholesterol regulates drug resistance

5. Clinical relevance of cholesterol in cancer

6. Strategies targeting cholesterol metabolism to overcome cancer resistance

7. Concluding remarks and future directions

\section{Introduction}

At present, cancer remains a serious threat to human life and poses a significant burden to healthcare systems, and is gradually becoming the leading cause of disease-related mortality. A previous study assessing the global burden of 29 types of cancer in 195 countries from 1990-2017 demonstrated that, when combining all types of cancer in most countries, the average annual age standardized incidence rates notably increased with time (1); 24.5 million cancer new cases and 9.6 million cancer-related deaths were reported globally in 2017, and the most common types of cancer were non-melanoma skin cancer, lung cancer, breast cancer, colon cancer, prostate cancer, stomach cancer, liver cancer, cervical cancer, non-Hodgkin's lymphoma and bladder cancer (1). The development of drug resistance in cancer treatment is a major obstacle. While the initial treatment is successful, acquired or secondary resistance occurs during repetitive cycles of therapy, subsequently resulting in tumor progression in several patients. Additionally, tumor cells which develop resistance to a single chemotherapeutic drug will often exhibit resistance to other chemotherapeutic drugs, despite the different characteristics and targets of the second-line therapeutic (2). This phenomenon is termed multi-drug resistance (MDR), and is a significant contributor to the decreased success rates of combination therapeutic regimens.

Drug resistance results in a reduction of the therapeutic efficacy of the administered drugs, weakening the inhibitory effects of chemotherapy on the growth and survival of cancer cells, resulting in the failure of chemotherapy and potentially increasing the risk of cancer-related mortality. The emergence of MDR in advanced- and terminal-stage cancer is typically associated with a poor prognosis and reduced survival rates of patients (3). Thus, it is necessary to elucidate the underlying molecular mechanisms of resistance and to develop novel therapeutic approaches to counter these. MDR in cancer cells 
during chemotherapy may be associated with a diverse range of molecular mechanisms, including enhanced drug efflux (4), decreased drug uptake by influx transporters such as solute carriers (5), alterations in drug metabolism (6), the inactivation of death signaling pathways (7), the mutation of drug targets (8), genetic factors and changes in the tumor microenvironment $(9,10)$.

Cholesterol is a significant component of plasma membranes and a precursor of steroid hormones and bile acids. Cholesterol is considered to play a vital role in human life (11). Cholesterol has been shown to accumulate in malignant tissues, and this is now considered a common characteristic of cancer cells (12). Recently, mechanistic investigations have demonstrated that cholesterol pathways are involved in the development of MDR in cancer cells $(13,14)$. Furthermore, epidemiological studies have suggested that combination chemotherapy (including targeted therapy) and cholesterol-lowing drugs improve survival times and lower cancer mortality rates $(15,16)$. The present review focuses on the roles of cholesterol as signaling molecules in the regulation of cancer drug resistance and the therapeutic potential of lowering cholesterol levels in cancer treatment.

\section{Cholesterol metabolism}

Cholesterol synthesis. Cholesterol plays a crucial role in life, performing numerous roles. including serving as a structural component of membranes to function as a precursor for several compounds, such as vitamin D, bile acids or steroid hormones. Cholesterol synthesis occurs through the mevalonate pathway, in which the progress of synthesis is rate-limited by various enzymes and transcription factors (17).

The first step in cholesterol synthesis is the formation of mevalonate from acetate (18). Acetyl-CoA is produced from the glycolysis of glucose in the mitochondria, and the remaining steps of cholesterol synthesis occur in the endoplasmic reticulum (ER) and cytoplasm (19). Acetyl-CoA condenses with acetoacetyl-CoA to form hydroxyl-methyl-glutaryl-coenzyme A (HMG-CoA) which is catalyzed by HMG-CoA reductase (HMGCR/HMGR). HMGCR is not only the rate-limiting enzyme for the reduction of $\mathrm{HMG}-\mathrm{CoA}$ to mevalonate, but is also a committal step for the entire process. Mevalonate acts as a precursor of numerous products, such as geranyl-pyro-phosphate and farnesyl-pyrophospate, both of which can induce the isoprenylation of the intracellular $G$ proteins Ras and Rho, which in-turn modulates cell proliferation and apoptosis (20). The following step is the conversion of mevalonate into squalene; mevalonate kinase forms mevaonate-5-phosphate from mevalonate (21). Following a series of successive condensation reactions of activated isoprenes, squalene is formed in the presence of squalene synthase. To form cholesterol, squalene has to initially undergo reactions in which squalene monooxygenase (SQLE) and lanosterol synthase catalyze the transformed squalene into cholesterol following several successive reactions (22).

In order to maintain the balance of cholesterol homeostasis in the plasma and intracellular membrane, with the involvement of enzyme, acyl-CoA acyl-transferase (ACAT) in the ER, free cholesterol is converted into cholesterol esters, which are stored as cytosolic lipid droplets when their levels increase above the threshold, and is used as cholesterol ester hydrolase when required (23). The disposal of cholesterol through $7 \alpha$-hydroxylated bile acids exerts a significant effect on cholesterol homeostasis. $7 \alpha$-hydroxylation is catalyzed by the enzyme, cytochrome P450 7A1 (CYP7A1), which also promotes the excretion of fecal sterols (24).

Statins are competitive inhibitors of HMGCR, the rate-limiting enzyme of the mevalonate pathway required for the biosynthesis of cholesterol (25). Recently, several preclinical studies discovered that the cholesterol levels in drug-resistant cell lines were considerably higher than those in drug-sensitive cell lines (26-28). Additionally, an additive effect of statins in terms of the inhibition of cell proliferation was observed; the related statins are presented in Table I. Multiple mechanisms connected with cholesterol have been identified, which lead to drug resistance in different types of cancer. Serum cholesterol levels, as well as intracellular cholesterol levels appear to be crucial in cancer drug resistance.

Cholesterol influx. To sustain whole-body cholesterol levels within a physiological range, lipoproteins mediate the management and delivery of dietary cholesterol to cells. In addition to de novo synthesis, cells capture cholesterol through the uptake of circulating plasma lipoproteins via low-density lipoprotein receptor (LDL-R) and scavenger receptor class B type I (SR-BI).

LDL-R, which is present on the plasma membrane of the majority of cells, is the major endocytic route for uptake of exogenous cholesterol. LDL or other apolipoprotein E/apolipoprotein B-containing lipoproteins bind to the LDL-R, and the complex is endocytosed by clathrin-coated vesicles. LDL becomes disassociated in the early endosome, and the LDL-R is recycled back to plasma membrane. As the early endosome progresses into a late endosome/lysosome, the non-recycled cholesterol is delivered to other organs, such as the ER, mitochondria and plasma membrane $(37,38)$. SR-BI has been shown to be of utmost importance in mediating the uptake of cholesterol from high-density lipoprotein (HDL). HDL binds to an HDL-receptor with a high affinity (39). SR-BI is expressed primarily in the liver and non-placental steroidogenic tissues and mediates selective cholesterol uptake by a mechanism distinct from the classical LDL receptor pathway (40). Although SR-BI binds to a variety of ligands, including HDL, LDL, very low-density lipoproteins and modified lipoproteins, the most important property of SR-BI is considered its ability to function as an HDL receptor.

Niemann pick C1-like 1 (NPC1L1), a protein which is localized at the brush border membrane of enterocytes, is responsible for absorption of free cholesterol into cells. In humans, it is also expressed in the liver, where it transports newly secreted biliary cholesterol back into the hepatocytes, and prevents the loss of endogenous cholesterol (41).

Cholesterol efflux. To prevent cholesterol retention, excess cellular cholesterol from cells is removed. As cells cannot degrade cholesterol, reverse cholesterol transport (RCT), a mechanism through which redundant cholesterol is transported from peripheral tissues to the liver for reuse or excretion, is necessary for cholesterol homeostasis (42). It has been shown that ABC transporters, one of the largest families of integral plasma membrane 
Table I. Combination of chemotherapeutic drugs and statins in different cancer entities.

\begin{tabular}{|c|c|c|c|c|c|}
\hline First author, year & $\begin{array}{l}\text { Chemotherapeutic } \\
\text { drug }\end{array}$ & Statin & In vitro & In vivo & (Refs.) \\
\hline Yun et al 2019 & Doxorubicin & Simvastatin & $\begin{array}{l}\text { Human epidermoid } \\
\text { carcinoma cell }\end{array}$ & $\begin{array}{l}\text { BLAB-C nu/nu } \\
\text { mice with A431 }\end{array}$ & $(29,30)$ \\
\hline Greife et al 2015 & & & $\begin{array}{l}\text { line, A431; Human } \\
\text { bladder cancer cell } \\
\text { line, BFTC-905-DOXO-II }\end{array}$ & & \\
\hline Kong et al 2018 & Enzalutamide & Simvastatin & $\begin{array}{l}\text { Human prostate cancer cell } \\
\text { lines, MR } 49 F / C 4-2 R / 22 R V 1\end{array}$ & Nude mice with 22RV1 & $(31)$ \\
\hline Kim et al 2019 & Paclitaxel & Simvastatin & Human cell line, A549T & $\begin{array}{l}\text { BLAB/C nude mice with } \\
\text { A549/T }\end{array}$ & $(32)$ \\
\hline Gupta et al 2018 & Paclitaxel & Lovastatin & & $\begin{array}{l}\text { Athymic nude mice with } \\
\text { human pancreatic cancer } \\
\text { cell line, SU.86.86 }\end{array}$ & (33) \\
\hline $\begin{array}{l}\text { Glodkowska-Mrowka } \\
\text { et al } 2014\end{array}$ & Imatinib & Lovastatin & $\begin{array}{l}\text { Human chronic myeloid } \\
\text { leukemia cell line, K562 }\end{array}$ & & (34) \\
\hline Chen et al 2015 & Cetuximab & Nystatin & $\begin{array}{l}\text { Human epidermoid carcinoma } \\
\text { cell line, A431; human } \\
\text { pulmonary adenocarcinoma } \\
\text { cell line, A549; human colon } \\
\text { carcinoma cell line, HCT-116 }\end{array}$ & $\begin{array}{l}\text { BLAB/C nude mice with } \\
\text { A431/A549 }\end{array}$ & $(35)$ \\
\hline Chen et al 2016 & Docetaxel & Atorvastatin & $\begin{array}{l}\text { Human prostate carcinoma } \\
\text { cell lines, } \mathrm{PC}-3 / \mathrm{LNCaP}\end{array}$ & & (36) \\
\hline Chen et al 2018 & Gefitinib & Lovastatin & $\begin{array}{l}\text { Human non-small cell } \\
\text { lung cancer cell } \\
\text { lines, H1975/PC-9-GR }\end{array}$ & $\begin{array}{l}\text { BLAB/C nude mice with } \\
\text { H1975 }\end{array}$ & (28) \\
\hline
\end{tabular}

NSCLC, non-small cell lung cancer.

proteins, are involved in the cholesterol transport across the cell membrane. The dysfunction of ATP-binding cassette (ABC) transporters may contribute to various cholesterol-related diseases. For example, mutations in ABC, subfamily A, member 1 (ABCA1) result in familial HDL deficiency (43).

ABCA1 promotes cholesterol efflux to extracellular acceptors, such as apolipoprotein A1, resulting in the formation of HDL particles; the first step in RCT (44). Synergistic mediation of ABCA1 and ABC, subfamily G, member 1 (ABCG1) for cholesterol efflux to HDL has been shown (45). Additionally, studies have demonstrated that the combined actions of ABCA1 and ABCG1 contributes to the maturation of HDL through the addition of cellular lipids to the nascent particles in macrophages (46). Two other ABC transporters, ABCG5 and ABCG8, which are both expressed on the brush border membrane of enterocytes and the canalicular membrane of hepatocytes, transport cholesterol from enterocytes into the gut lumen for fecal disposal (47).

Of note, SR-BI can mediate the bi-directional exchange of free cholesterol between cells and HDL (48). For example, J774 macrophages stably overexpressing SR-BI have been shown to export more cholesterol to HDL than the controls, indicating the potential role of SR-BI in cholesterol efflux (49).
Transcriptional regulation of cholesterol synthesis-related genes. In mammary tissues, the homeostatic control of cholesterol is reflected in the balance of biosynthesis, and the influx and efflux of cholesterol. The balance is primarily regulated by the cooperation of two transcription factor families: The sterol regulatory element-binding proteins (SREBPs) and the liver X receptors (LXRs) $(50,51)$.

SREBP family members are synthesized as membrane proteins in the ER, and SREBP2 primarily regulates the transcription of genes involved in cholesterol biosynthesis, and its activity is controlled via a negative feedback loop (52). Under sterol-rich conditions, SREBP is sequestered by the SREBP-cleavage-activating protein (SCAP) in the ER, in which SCAP binds to the insulin-induced gene (INSIG) and this interaction traps SREBP in the ER membrane. However, when cholesterol levels decrease below homeostatic levels, SCAP dissociates from INSIG and escorts SREBP to the Golgi where the complex is cleaved, subsequently leading to the translocation of the mature transcription factor to the nucleus and transcription of SREBP-targeted genes, such as HMGCR and LDL-R (Fig. 1) $(53,54)$.

In addition to SREBPs, LXRs, which are members of the nuclear receptor superfamily, also participate in cholesterol metabolism. LXRs are activated by endogenous ligands, 


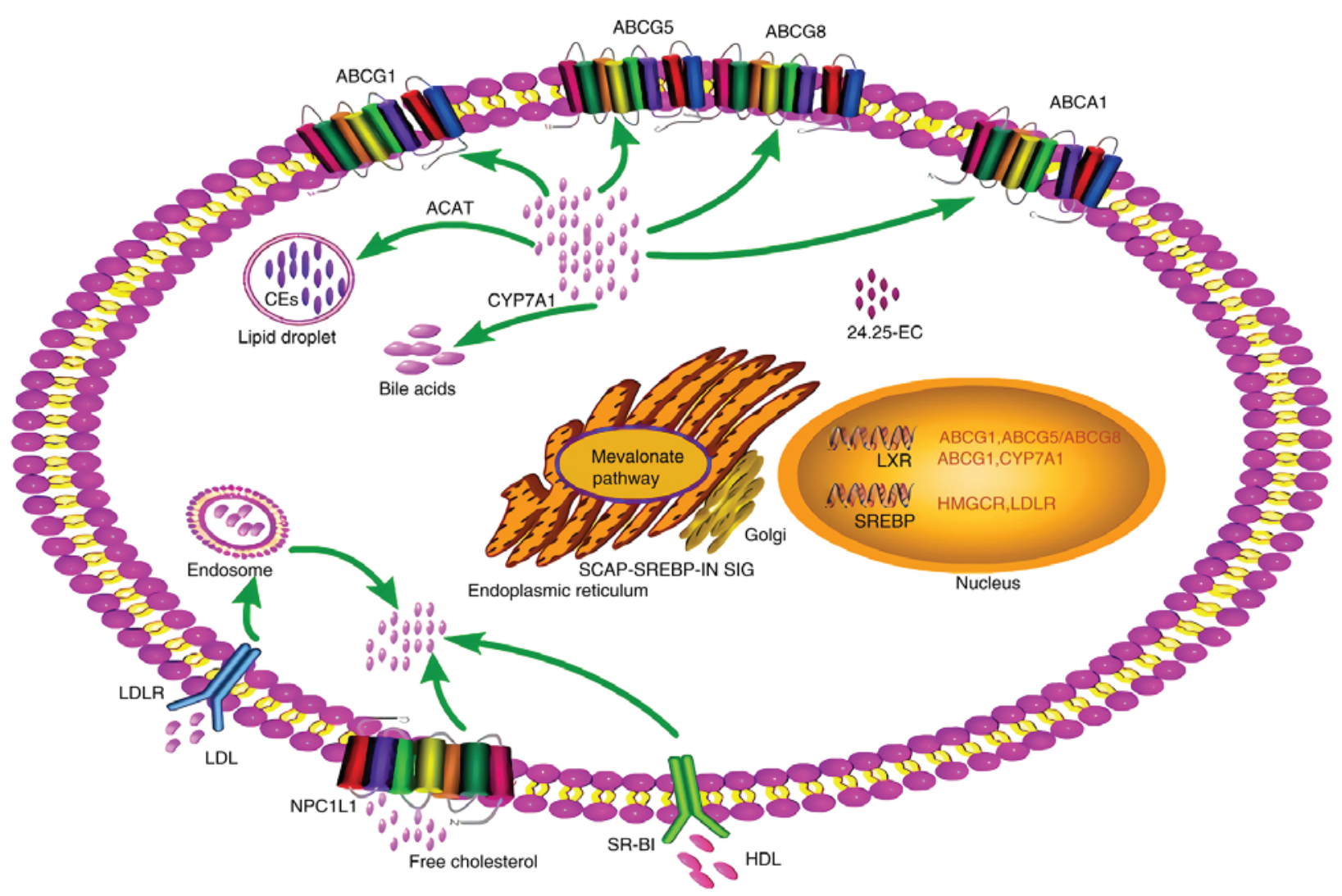

Figure 1. Regulation of cholesterol metabolism through modulation of intracellular sterol levels. Under conditions of high sterol levels, endogenous ligands activate LXRs, thus upregulating the expression of transporters such as ABCG1, ABCG5/G8 and ABCA1 to mediate cholesterol efflux. Additionally, LXRs target CYP7A1 to transform cholesterol into bile acids. Excess sterols are converted into esters and stored within lipid droplets. Conversely, under conditions of low sterol levels, the SCAP-SREBP complex migrates to the Golgi and is cleaved, releasing SREBP, resulting in the migration of the mature transcription factor to the nucleus and the transcription of SREBP-targeted genes, such as members of the HMGCR activating mevalonate pathway and LDL-R enhancing exogenous cholesterol capture. ABC, ATP binding cassette; LXR, liver X receptor; SREBP, sterol regulatory element binding protein; SCAP, SREBP-cleavage-activating protein; HMGCR, hydroxyl-methyl-glutaryl-coenzyme A reductase; LDL-R, low density lipoprotein-receptor.

includingoxysterols, desmosterol,and24S,25-epoxycholesterol. Once activated, LXRs upregulate the transcriptional levels of genes involved in cholesterol transport, including ABCA1, ABCG1, ABCG5 and ABCG8 (Fig. 1) (50). When intracellular cholesterol levels exceed physiological limits, LXRs facilitate the transcription of the aforementioned target genes and thus RCT, thereby functioning to maintain homeostatic levels (55). Furthermore, CYP7A1, which catalyzes the formation of bile acids, is a target gene of LXRs (Fig. 1). LXR activation can downregulate NPC1L1 expression in human enterocytes, accompanied by the reduction of cholesterol absorption (56).

\section{Role of cholesterol in drug resistance in cancer}

The association between cholesterol homeostasis and drug resistance has been the subject of numerous studies. Recently, using data obtained from The Cancer Genome Atlas, it was demonstrated that there was an association between cholesterol synthesis and a decreased patient survival, as well as progression in patients with cancer $(57,58)$. Considering the role of cholesterol in cancer development and the adverse outcomes of MDR in cancer patients, it is necessary to examine the role of cholesterol in cancer drug resistance (14).

Preclinical studies have also demonstrated the role of cholesterol in drug resistance in several types of cancer, including prostate, pancreatic, bladder and breast cancer, amongst others $(30,31,59-61)$.

In breast cancer, aromatase inhibitor-resistant cells exhibit activated endogenous cholesterol biosynthesis, resulting in the constitutive activation of estrogen receptor- $\alpha$; estrogen receptor- $\alpha$ binding can be reduced using statins, which in-turn reduces cell invasion. Furthermore, patients with high levels of cholesterol biosynthesis are less likely to benefit from treatment with aromatase inhibitors (62). Another example in breast cancer includes the association between tamoxifen resistance and cholesterol. As previously demonstrated, in tamoxifen-resistant cells, the expression of peroxisome proliferator-activated receptor- $\gamma$, which regulates several lipid droplet proteins, is altered, and the expression of ABCA1, which functions a cholesterol efflux pump, is downregulated. Notably, a substantial increase was also observed in neutral lipids (cholesterol esters and triglycerides), as well as an accumulation of free cholesterol in the resistant cells (60). Similar results have been reported in non-small cell lung cancer cells, where cholesterol levels in gefitinib-resistant cells were notably higher than in the gefitinib-sensitive cells (28). Notably, it has been reported that radioresistance in pancreatic cancer cells is associated with the expression of ACAT-2, fatty acid synthesis (FASN) and SQLE at the mRNA level, all of which are involved in cholesterol homeostasis, suggesting that 


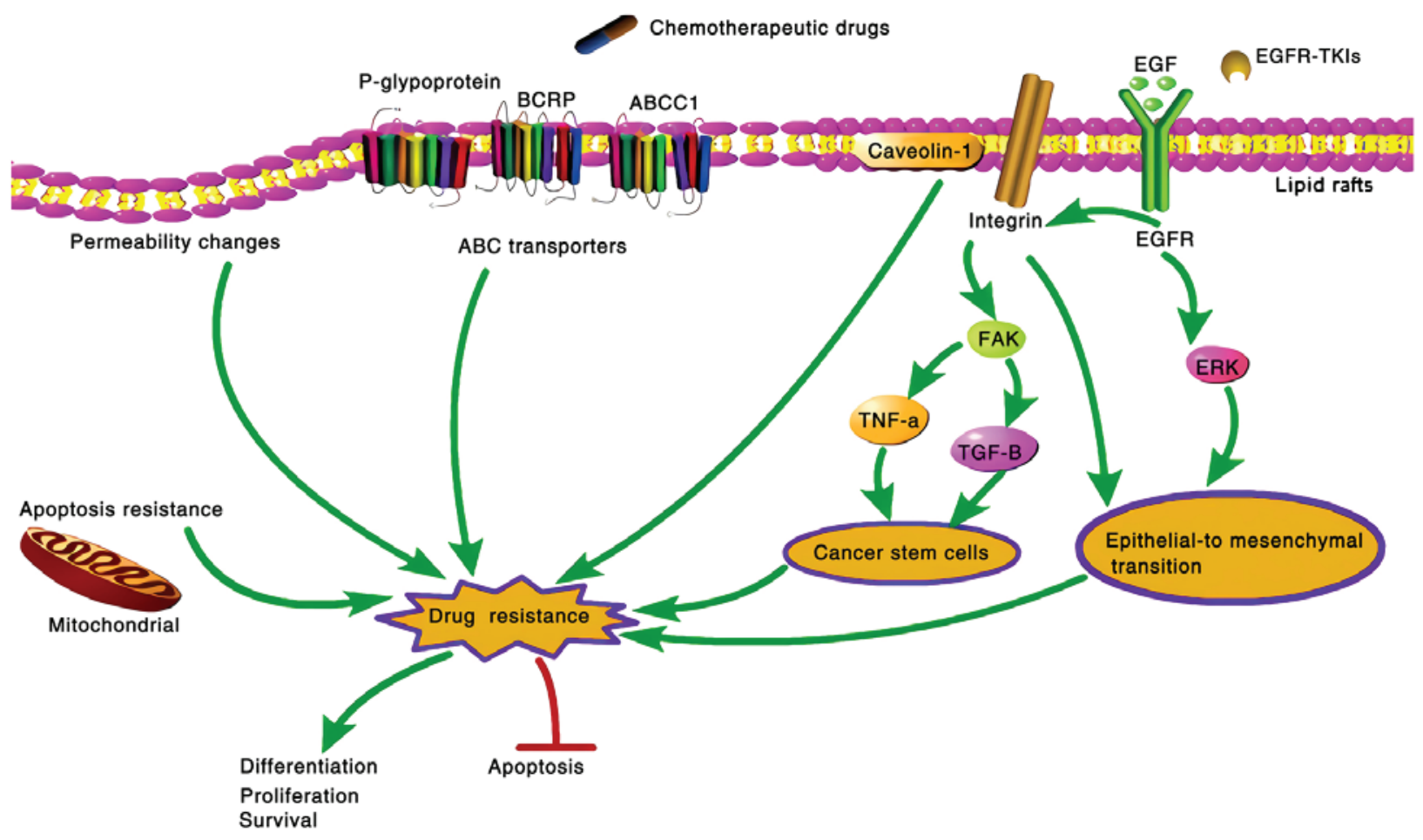

Figure 2. Mechanisms through which cholesterol regulates drug resistance in cancer cells. Cholesterol regulates drug resistance in cancer cells via different mechanisms. Elevated mitochondrial cholesterol levels can induce resistance to apoptotic signals. Moreover, cholesterol levels in lipid rafts regulate related signal transduction pathways, such as the EGFR signaling pathway and caveolin-1, leading to epithelial-mesenchymal transition or acquisition of cancer-stem cell like properties. As the cholesterol composition of the cellular membrane is altered, the function of ABC transporters (p-glycoprotein, BCRP and ABCC1) is changed accordingly. In addition, the change in cholesterol content in cell membranes may affect the permeability to therapeutic drugs and the uptake of agents. Eventually, drug resistance in cancer cells influences survival, proliferation, differentiation and apoptosis. ABC, ATP binding cassette; EGFR, epidermal growth factor receptor.

cholesterol may also be associated with radioresistance (63). The expression of HMGCR, a crucial enzyme in the mevalonate pathway of cholesterol synthesis, is increased in enzalutamide-resistant prostate cancer cell lines, and HMGCR knockdown or HMGCR inhibition has been shown to result in the re-sensitization of resistant cells to enzalutamide, whereas HMGCR overexpression confers resistance to the drug (31). The induction of the mevalonate pathway has also been reported as a mechanism of doxorubicin resistance in bladder cancer, and co-treatment with simvastatin restores the sensitivity of resistant cells to doxorubicin (30). Doxorubicin downregulates HMGCR protein levels, resulting in decreased levels of cholesterol, which is associated with the inactivation of the epidermal growth factor receptor (EGFR)-src pathway (29). Furthermore, HMGCR inhibition or knockdown enhances doxorubicin toxicity (29), and these results are in accordance with those of aforementioned studies $(30,31)$. In addition to cholesterol, the increased accumulation of cholesterol esters has also been observed in drug-resistant pancreatic ductal adenocarcinoma and chronic myelogenous leukemia, and cholesterol esterification inhibition enhances the sensitivity to gemcitabine and imatinib $(59,64)$.

Elevated cholesterol levels in the mitochondria have been shown to confer resistance to apoptotic signals, thus contributing to chemotherapeutic resistance in several types of cancer (Fig. 2) $(26,65,66)$. The mitochondrial cholesterol content in cases of hepatoma has been shown to be notably increased compared with that of normal tissues (67). Furthermore, the mitochondria of hepatocellular carcinoma cells, which are resistant to mitochondrial membrane permeabilization and other various stimuli, exhibit increased cholesterol levels. The sensitivity of cells to chemotherapy increases upon cholesterol depletion through the inhibition of HMGCR or SQLE. In a previous study, when steroidogenic acute regulatory protein, a mitochondrial cholesterol-transporting polypeptide that is upregulated in hepatocellular carcinoma cells, was knocked down by small interfering RNA, the cells exhibited increased sensitivity to chemotherapy (26). Another previous study using animal experiments also confirmed that cholesterol overload in the liver contributed to mitochondrial changes, which ultimately conferred resistance to cell death (65).

However, another previous in vitro study demonstrated an opposite effect of cholesterol on drug resistance (68). Combined treatment with cholesterol and temozolomide reversed temozolomide resistance, whereas clinical anti-hypercholesterolemia agents (lovastatin or simvastatin) suppressed temozolomide-induced cell death. These conflicting results suggest drug resistance mediated by elevated cholesterol levels may be restricted to certain cancer types.

\section{Mechanisms through which cholesterol regulates drug resistance}

Lipid rafts. In addition to serving as a precursor for steroid hormones and a key component of the plasma membrane, cholesterol also plays an essential role in intracellular signal 
transduction (69). The regulation of signal transduction pathways in cancer resistance by cholesterol, to a certain degree, is partly due to membrane microdomains termed lipid rafts, which are characterized by the enrichment of cholesterol and sphingolipids, resulting in a lipid phase that is more ordered than the surrounding membrane (70). A wide number of transduction signals related to cell survival and proliferation, have been reported to be connected with lipid rafts, such as receptor tyrosine kinases, platelet-derived growth factor receptor and EGFR. Of note, cancer cells possess higher numbers of lipid rafts than their normal counterparts, and the cholesterol levels in lipid rafts of drug-resistant cancer cells are higher than drug-sensitive cancer cells $(28,71)$. Thus far, there are numerous studies available on cancer resistance is mediated through lipid rafts, within which signaling molecules associated with cell proliferation, apoptosis, invasion and migration, are impeded by cholesterol changes, as described below.

In non-small cell lung cancer, the sensitivity of gefitinib, an EGFR-tyrosine kinase inhibitor, has been shown to be affected by cholesterol levels in lipid rafts. Following the depletion of cholesterol in lipid rafts, gefitinib-resistant cell lines exhibit a high affinity for gefitinib and EGFR, leading to an enhanced sensitivity to gefitinib, as well as to the decreased phosphorylation of AKT, MEK1/2 and ERK1/2 (28). The attenuation of EGFR signaling is attributed to multiple mechanisms, one of which is endocytosis, a process through which receptors are removed from the cell surface and delivered to sites of inactivation, such as through ER-based phosphatases (72). Clathrin-independent endocytosis is activated by high levels of EGF, but is also dependent on the cholesterol levels in the membrane (73). Thus, sensitivity to gefitinib may be mediated by cholesterol via endocytosis. Similarly, a study in multiple human carcinoma cell lines highlighted the presence of a mechanism whereby the uptake of an EGFR-targeting monoclonal antibody was improved through cholesterol sequestration, which also enhanced drug internalization by regulating EGFR trafficking/turnover and facilitating a switch from lipid rafts to clathrin-mediated endocytosis (35). ERK1/2 pathway activation mediated by EGFR, and adipocyte plasma membrane-associated protein (APMAP) accumulation are involved in the cholesterol-mediated induction of epithelial-mesenchymal transition (EMT) (Fig. 2). Mechanistically, APMAP increases the interaction between EGFR substrate15-related protein, inhibiting the endocytosis of EGFR by cholesterol, thus promoting EMT (74). Another example of the role of cholesterol in lipid rafts influencing EMT-associated drug resistance concerns cell adhesion proteins. Lipid raft disruption by simvastatin suppresses integrin- $\beta 3$ and focal adhesion formation, thus inhibiting the FAK signaling pathway and re-sensitizing drug-resistant cancer cells to paclitaxel, and repolarizes tumor-associated macrophages, increasing TNF- $\alpha$ and attenuating TGF- $\beta$, which ultimately results in the suppression of EMT (Fig. 2) (32). Of note, integrin signaling is also required for the maintenance of properties of cancer stem cells (CSCs) (Fig. 2) (75). CSCs are a subset of cells within the tumor which possess self-renewal, differentiation and tumorigenic capacity, often underlying the failure of cancer therapy and eventually resulting in tumor recurrence and eventually metastasis, due to their considerable chemoresistant properties (76). Taken together. these data indicate that cholesterol-rich lipid rafts may play a critical role in cancer drug resistance.

Caveolae, a specific subclass of lipid rafts, can be readily identified by the presence of the cholesterol binding protein, caveolin-1 (77). In pancreatic cancer cells, high caveolin-1 levels promote resistance to chemotherapeutic agents, such as gemcitabine and 5-fluorouracil (78). Caveolin-1 expression is upregulated in resistant colorectal cancer cells (79). In aggressive and metastatic prostate cancer, a high caveolin-1 expression increases acetyl-CoA carboxylase-1 and FASN expression in an androgen receptor-independent manner, suggesting that caveolin-1 promotes hormone resistance through the regulation of lipid synthesis (80). Cholesterol depletion using methyl- $\beta$-cyclodextrin potentiates the tamoxifen-induced anticancer effects, and this sensitization is associated with the downregulation of caveolin-1 (Fig. 2). Thus, cholesterol and caveolin-1 may interact and influence each other (81).

$A B C$ transporters. The importance of $\mathrm{ABC}$ transporters in the development of drug resistance in several types of cancer has been the subject of numerous studies spanning several decades. In view of their localization in the membrane, it has been hypothesized that the membrane environment of the transporters is crucial for their function. Several studies have demonstrated that when the cholesterol composition of the cellular membrane is altered, the function of these ABC transporters is altered accordingly.

In human peripheral blood mononuclear cells, elevated cellular cholesterol levels significantly increase p-glycoprotein activity (82). In addition, p-glycoprotein that has been reconstituted in cholesterol-containing liposomes, exhibit increased p-glycoprotein ATPase activity (83). In agreement with these findings, the removal of cholesterol, which modulates the membrane lipid composition, alters the localization of p-glycoprotein and results in the loss of p-glycoprotein function (Fig. 2) (84). Furthermore, in human CEM acute lymphoblastic leukemia cells, which exhibit varying degrees of chemoresistance, the amount of cholesterol ester increases linearly with the level of resistance to vinblastine, whereas the amounts of total and free cholesterol increase in a non-linear manner. Moreover, membrane cholesterol controls both ATPase activity and the drug efflux activity of p-glycoprotein. CEM cells that express increasing levels of elevated chemoresistance have been shown to increase the amount of p-glycoprotein to a peak of $40 \%$ of total membrane proteins and this remains unvaried (85). In terms of increasing the quantity of cholesterol in the membrane and its association with MDR, it has been strongly suggested that cholesterol may directly underlie the acquisition of a typical MDR phenotype. The mechanisms through which the presence of cholesterol enhances the activity of p-glycoprotein have also been the subject of numerous studies. Both the ability of drug binding to p-glycoprotein and drug transport are affected by cholesterol by altering the partitioning of hydrophobic drug substrates into the membrane and altering the local lipid environments of p-glycoprotein (86). A recent study found that $\mathrm{p}$-glycoprotein substrates may preferentially accumulate in cholesterol-rich regions of the membrane; thus, the transport activity of p-glycoprotein is increased in the presence of cholesterol (87). In agreement 
with this finding, in colon cancer cells, following the reduction of cholesterol synthesis and incorporation in detergent resistant membranes, the amount of p-glycoprotein, as well as transport activity, are decreased. The inhibition of cholesterol synthesis by simvastatin has been found to facilitate the degradation of $\beta$-catenin and decrease $p$-glycoprotein expression, subsequently contributing to the sensitivity to drugs in canine mammary CSCs (88). Of note, $\beta$-catenin is usually activated in CSCs and leads to the upregulation of p-glycoprotein (89).

Several studies have established an association between the levels of cholesterol and the activity of BCRP. A previous study found that the ATPase activity of human BCRP transfected sf9 cell membranes differed from that of BCRP-overexpressing human cell membranes, and that the lipid compositions of the two cell lines differed from each other (90). Of note, in both cell lines, cholesterol loading prominently improved drug transport into inside-out membrane vesicles, indicating the vital role of membrane cholesterol in the function of BCRP. A similar study later suggested that the cholesterol enrichment of cell membrane vesicles increases BCRP-driven substrate uptake, substrate-stimulated ATPase activity, as well as the formation of a catalytic cycle intermediate, also highlighting the importance of membrane cholesterol in BCRP transport activity (Fig. 2) (91). Analogous results have been found in human erythrocyte membranes in which lucifer yellow (a fluorescent BCRP substrate) uptake decreased when membrane cholesterol content was increased following treatment with cholesterol hemisuccinate (92). Taken together, it is reasonable to ascribe chemoresistance to cholesterol-induced BCRP expression.

ABC subfamily $\mathrm{C}$, member 1 (ABCC1) is another $\mathrm{ABC}$ transporter whose functionality appears to be regulated by cholesterol. It was suggested that $\mathrm{ABCC} 1$ functionality was associated with its localization in cholesterol-rich membrane microdomains, and depletion of membrane cholesterol below $40 \%$ caused a partial shift of ABCC1 to the high-density fraction, and decreased functionality (Fig. 2) (93). In this regard, there is some resemblance between BCRP and ABCC1, as their localization in the cell membrane and functionality is regulated by cholesterol.

Drug uptake is modulated by cholesterol. There have been some studies which have demonstrated the role of cholesterol in modulating the uptake of chemotherapeutic drugs. Compared with the parental cell line, vincristine-resistant cells exhibit lower rates of drug delivery in murine leukemic lymphoblasts. Furthermore, the cholesterol content in resistant cells is directly proportional to the relative resistance to vincristine; cholesterol depletion results in an increase in the rate of drug uptake, which is reversed by cholesterol reloading (94). Similar results have been found in breast cancer cells, where decreased cholesterol levels have been shown to result in the increased uptake of doxorubicin (27). A possible explanation for these findings is that the change in the cholesterol content in cancer cell membranes significantly affects their permeability to therapeutic drugs (Fig. 2) (95). The cholesterol-modulated uptake of chemotherapeutic agents is considered one of the mechanisms underlying the initiation of drug resistance.

\section{Clinical relevance of cholesterol in cancer}

Cholesterol levels in patients with drug-resistant cancer. The accumulation of cholesterol is a well-known feature observed in several types of cancer (96). The mechanisms through which cholesterol influences carcinogenesis have been extensively investigated for decades. Clinical studies have also suggested an association between cancer drug resistance and cholesterol levels in certain types of cancer. In lung cancer, compared with patients who exhibit the delayed acquisition of resistance, patients who acquire chemoresistance exhibit elevated serum levels of cholesterol at a relatively rapid rate (14). In breast cancer, cholesterol biosynthesis-related genes are progressively upregulated as the cancer progresses, and patients with high levels of cholesterol biosynthesis are unlikely to benefit from aromatase inhibitor treatment (62). Similarly, the increased expression of enzymes in the cholesterol biosynthesis pathway has been shown to be significantly associated with a poor response to endocrine therapy (97), and a high expression of cholesterol biosynthesis genes is an independent prognostic factor of shorter recurrence-free and overall survival (98). For patients with ovarian cancer, elevated cholesterol levels in ascites have been shown to be associated with chemoresistance, as well as shorter recurrence-free survival times (99). However, additional studies are required to fully determine the effects of cholesterol on cancer development and to elucidate the mechanisms through it modulates cancer drug resistance.

Prognostic significance of cholesterol in cancer. The prognostic significance of serum total cholesterol (TC), triglycerides (TG), HDL-C and LDL-C in cancer has been extensively studied. Recently, a systematic review and meta-analysis covering 26 studies, including 24,655 individuals, found that only the TC and HDL-C levels were significantly associated with cancer mortality (100). Similarly, the existing literature are more supportive of the role of TC and HDL-C as prognostic predictors than TG and LDL-C. Herein, the prognostic value of TC and HDL-C in different types of cancer are discussed (101-103).

A retrospective study comprising 184 patients with gastric cancer undergoing gastrectomy found that the patients in the low-HDL-C group had a significantly higher rate of gastric cancer mortality, as well as increased lymphatic and vascular invasion compared with the normal-HDL-C group (104). Moreover, a multivariate analysis of the factors influencing gastric cancer mortality rates revealed that the HDL-C value was an independent prognostic factor. In soft tissue sarcoma, both univariate and multivariate analysis revealed that decreased HDL-C levels were significantly associated with the decreased overall survival and decreased disease-free survival of patients with extensive and radical surgical resection, suggesting the potential prognostic utility of plasma HDL-C levels as an independent factor (105). Similarly, in breast cancer, the prognostic significance of HDL-C has been shown. A case-controlled study, including 1,081 patients demonstrated that HDL-C levels in the patient group were notably lower than those in the control group (106). For patients with triple-negative breast cancer, a higher proportion of HDL-C to TC represents a lower overall risk of mortality. However, no associations have been observed between 
HDL-C and prognostic outcome amongst all the breast cancer cases (including luminal A, luminal B, HER2-enriched and triple-negative breast cancer), suggesting that the impact of pre-diagnostic HDL-C on breast cancer recurrence and survival may be limited by cancer subtype (102). In agreement with these studies, a recent meta-analysis demonstrated that disease-free survival and overall survival were increased in patients with high HDL-C levels compared with patients with low HDL-C levels. Across the included types of cancer (breast cancer, lung cancer, hepatocellular carcinoma and renal cell carcinoma), the most prominent prognostic effect of HDL-C was observed in lung cancer (100). The HDL-C level has emerged as a valuable prognostic factor in different types of cancer, and the clinical value of HDL-C levels requires further verification.

The prognostic role of TC also has been established by numerous independent studies. The negative association of serum cholesterol levels with cancer mortality was previously investigated in a prospective study as early as 1980 (107). Similar results were later found in the multiple risk factor intervention trial (108). In a study on gastric cancer, the serum cholesterol levels were significantly lower in the cancer patients compared with the healthy subjects. Additionally, decreased levels of cholesterol were accompanied by tumor progression, suggesting that serum cholesterol levels may be used as a marker of cancer progression (109). In clear cell renal cell carcinoma, lower pre-operative serum TC levels were associated with a lower recurrence-free survival and cancer-specific survival rates. Furthermore, multivariate analysis indicated that serum TC levels were an independent predictor of clear cell renal cell carcinoma (110). A study on 198 patients with non-small cell lung cancer revealed the prognostic role of pre-operative TC levels in both univariate and multivariate analysis. Lower serum TC levels were shown to be associated with shorter overall survival times (111). Conversely, a positive association between high levels of TC and overall mortality has been observed in breast cancer patients (103). Given the contrasting results based on the type of cancer studied, the prognostic role of TC requires further investigations; however, it appears to be cancer type-specific.

\section{Strategies targeting cholesterol metabolism to overcome cancer resistance}

The characteristics of cholesterol, as well as its involvement in several mechanisms associated with drug resistance in various types of cancer are discussed below. Targeting cholesterol homeostasis pathways is a potential target for modulating drug resistance. Examples of drugs targeting cholesterol homeostasis pathways are summarized in Table II.

Targeting cholesterol synthesis. Multiple enzymes and proteins are involved in cholesterol homeostasis as mentioned above. Therapeutic drugs targeting cholesterol synthesis have been investigated, and statins are the most extensively studied class. Statins are potent competitive inhibitors of HMGCR, with exhibit synergistic activity with numerous chemotherapeutic agents, preventing the development of MDR in cancer cells. For example, lovastatin synergistically potentiates the anti-leukemic activity of imatinib with chronic myeloid leukemia cells from patients with different stages of the disease, including those resistant to imatinib (34). The effect was ascribed to increased intracellular concentration of imatinib through lovastatin, inhibiting efflux of the drug by $A B C B 1$ and ABCG2. Several retrospective studies have demonstrated that statin use is associated with the prognosis and survival of various types of cancer, and the benefit of drugs appears to be statin-type and follow-up time dependent $(15,16,112,113)$. A recent example of a cohort study of patients with endometrial cancer demonstrated that, compared with patients who had never used statins, the continuous use of statins (pre-diagnosis and post-diagnosis) and those who had only used statins at post-diagnosis, exhibited reduced mortality rates and an improved survival (15). More comprehensive studies are required to confirm the benefits of statins in cancer.

Omega 3 polyunsaturated fatty acids docosahexaenoic acid (DHA) is another therapeutic targeting the ubiquitination of HMG-CoA reductase, thus reducing cholesterol biosynthesis. It has been shown that DHA restores the antitumor effects of different chemotherapeutic drugs in MDR cells (88).

Farnesyl diphosphate synthesis (FDPS) is a key enzyme involved in cholesterol biosynthesis. Alendronate and zoledronate, which both inhibit FDPS, significantly reduce the formation and the embryonic stem cell signature of glioblastoma spheres (114). The acquisition of stem-cell-like characteristics (stemness) has been hypothesized to be closely associated with the chemoresistance of glioblastoma. Protein geranylgeranylation, a branch of the cholesterol synthesis pathway, has been found to be critical for breast CSC maintenance. An inhibitor of the geranylgeranyl transferase I (GGTI) enzyme, GGTI-288, reduces the CSC subpopulation in breast cancer both in vitro and in primary breast cancer xenografts (115). Taken together, these preclinical studies suggest that targeting cholesterol synthesis pathways may be beneficial for modulating drug resistance.

Targeting cholesterol transport. Preclinical studies have demonstrated the potential of disrupting cholesterol transport in cancer chemotherapy. LXR, which plays key roles in the regulation of the expression of $\mathrm{ABC}$ transporters, is implicated in cholesterol efflux as mentioned above. LXR agonists, including T0901317, 22(R)-hydroxycholesterol and conjugated linoleic acids (CLA) isomers (t9 and t11-CLA), inhibit the proliferation of multiple types of cancer cells by increasing the expression of LXR target proteins (such as ABCA1 and ABCG1) involved in cholesterol efflux, thus reducing the intracellular and membrane-associated cholesterol levels (116-118). Lycopene increases the protein and mRNA expression levels of LXR and ABCA1 in androgen-independent prostate cancer cells. Moreover, the combination of lycopene and T0901317 has been shown to exert synergistic effects on cell proliferation (116). Notably, etoposide and teniposide, which are DNA topoisomerase II inhibitors that are frequently used in the treatment of various types of cancer, have been reported to increase the expression of ABCA1 and ABCG1 in macrophages in vitro and to enhance RCT from macrophages to the feces in vivo, highlighting the potential role of ABCA1 and ABCG1 in anti-tumorigenesis (119). 
Table II. Agents targeting cholesterol in different types of cancer.

\begin{tabular}{|c|c|c|c|c|c|}
\hline \multirow{2}{*}{$\begin{array}{l}\text { First author, year } \\
\text { Glodkowska-Mrowka } \\
\text { et al } 2014\end{array}$} & \multicolumn{2}{|c|}{$\begin{array}{c}\text { Cholesterol-related } \\
\text { targets }\end{array}$} & \multirow[t]{2}{*}{ Agent } & \multirow{2}{*}{$\begin{array}{l}\text { Cancer } \\
\begin{array}{l}\text { Chronic myeloid } \\
\text { leukemia }\end{array}\end{array}$} & \multirow{2}{*}{$\frac{(\text { Refs.) }}{(34)}$} \\
\hline & Synthesis & HMGCR & & & \\
\hline Gelsomino et al 2013 & & & DHA & Colon cancer & $(88)$ \\
\hline Kim et al 2018 & & FDPS & Alendronate, zoledronate & Glioblastoma & $(114)$ \\
\hline Ginestier et al 2012 & & GGTI & GGTI-288 & Breast cancer & $(115)$ \\
\hline Yang et al 2016 & Transport & LXRs & T0901317 & Prostate cancer & $(116)$ \\
\hline El Roz A et al 2012 & & & 22(R)-hydroxycholesterol & Breast cancer & $(117)$ \\
\hline El Roz A et al 2013 & & & t9, t11-CLA, Lycopene & Breast cancer & $(118)$ \\
\hline Kuzu et al 2014 & & NPC1 & Leelamine & Colon cancer, melanoma & $(121)$ \\
\hline Rios-Marco et al 2013 & & & Alkylphospholipids, itraconazole & Glioblastoma & $(123,124)$ \\
\hline Liu et al 2014 & & & & & \\
\hline Kuzu et al 2017 & & & Perphenazine & Melanoma & $(125)$ \\
\hline Solomon et al 2009 & Absorption & & Ezetimibe & Prostate cancer & $(131)$ \\
\hline Xu et al 2016 & & & SC09 & Multiple myeloma & $(132)$ \\
\hline Li et al 2018 & Esterification & ACAT-1 & Avasimibe & $\begin{array}{l}\text { Chronic myeloid } \\
\text { leukemia }\end{array}$ & (59) \\
\hline
\end{tabular}

HMGCR, hydroxyl-methyl-glutaryl-coenzyme A reductase; DHA, Omega 3 polyunsaturated fatty acids docosahexaenoic acid; FDPS, farnesyl diphosphate synthesis; GGTI, geranylgeranyl transferase I; LXR, liver X receptor; NPC1, Niemann-Pick type C1; ACAT-1, acyl-CoA acyl-transferase-1.

NPC1 is a transmembrane efflux pump involved in cholesterol trafficking. Previous studies have indicated that NPC1 is associated with resistance against imatinib in acute lymphoblastic leukemia cells (120). It was demonstrated that leelamine mediated cancer cell death through inhibiting autophagic flux and inducing cholesterol accumulation in lysosomal/endosomal cell compartments (121). A subsequent study found that the active derivatives of leelamine hindered xenografted melanoma tumor development by binding to NPC1 (122). Alkylphospholipids, itraconazole and perphenazine are examples of inhibitors targeting intracellular cholesterol transport, which in preclinical studies suppresses tumor cell growth by disrupting autophagic flux and inducing autophagy (123-125). The potential of these agents in suppressing melanoma cells or modulating cancer resistance remains to be determined, as well as the clinical value of targeting cholesterol transport.

Other cholesterol-directed treatment approaches. The role of dietary cholesterol in cancer development and prognosis is contested. A recent study found that a high-cholesterol-diet attenuated the anticancer activity of doxorubicin in epidermoid carcinoma xenografts (29). Several case-control studies have suggested a positive association between the risk of several types of cancer and dietary cholesterol uptake (126-129). However, several other studies have not found any evidence of an association between dietary cholesterol intake, and the risk of lung cancer and ovarian cancer $(127,130)$. Furthermore, dietary surveys may be unreliable. Based on the above, the effect of increased dietary cholesterol on the development of cancer requires further study. The inhibition of intestinal cholesterol absorption reduces the levels of cholesterol in cancer cells. For example, ezetimibe, an FDA-approved drug for blocking cholesterol uptake, reduces the growth of human prostate cancer xenograft tumors by inhibiting cholesterol absorption (131). Similarly, in a separate study, the tumor-promoting effects of a Western diet on human xenografts were reduced when ezetimibe was used to inhibit the intestinal uptake of cholesterol (126). SC09, an inhibitor of cholesterol absorption, has been shown to induce multiple myeloma cell death in vitro and attenuate multiple myeloma tumor growth in vivo (132). While targeting dietary cholesterol uptake reduces tumor development in preclinical studies, the clinical efficacy of this approach requires further validation.

Targeting cholesterol esterification inhibition is another method with which to reduce cancer resistance. For example, avasimibe, a potent inhibitor of ACAT-1, combined with imatinib, has been shown to result in a significant synergistic inhibition of cell proliferation in chronic myelogenous leukemia (64). The synergistic effects were confirmed in a xenograft mouse model. Of note, similar results have been observed in pancreatic ductal adenocarcinoma when avasimibe was used in combination with gemcitabine (59).

\section{Concluding remarks and future directions}

The potential causative factors and therapeutic strategies of cancer and cancer drug resistance are both substantial healthcare concerns. To date, numerous studies have demonstrated the significant role of cholesterol in cancer development $(57,58)$. The effect of cholesterol on the acquisition of drug resistance in cancer is increasingly being studied. Increased cholesterol 
levels, as well as altered protein expression levels are involved in cholesterol metabolism and have been observed in various types of chemoresistant cancer cells. These proteins include FASN, SQLE, ACAT and HMGCR, amongst others. The mechanisms through which increased cellular cholesterol levels enhance drug resistance are summarized as follows: i) Lipid rafts/caveolae disruption induces altered signal transduction in several cellular behaviors including apoptosis, invasion and proliferation; ii) The improved functionality of $\mathrm{ABC}$ transporters accelerates the efflux of chemotherapeutic drugs from cancer cells; and iii) Decreased membrane permeability to therapeutic agents directly results in reduced drug uptake (Fig. 2). Furthermore, epidemiological studies (106-108) have provided additional support for the use of cholesterol as a prognostic factor for certain cancer types, indicating the importance of regulating cholesterol homeostasis.

Lipids are a varied class of molecules, which include cholesterol. Over the past few years, the importance of lipids in various aspects of cancer biology has been elucidated, and lipid signal mediators involved in the development of cancer drug resistance have garnered increasing attention. In addition to cholesterol, other types of lipids, including fatty acids and sphingolipids have also been shown to participate in drug resistance. FASN is the major lipogenic enzyme catalyzing the synthesis of fatty acids. The inhibition of FASN-driven lipid rafts negatively affects EGFR-her2/neu crosstalk, thus reducing trastuzumab resistance (133). In a spontaneous pancreatic cancer mouse model, a significant increase in FASN expression was associated with increased disease progression (134). In accordance with this, a high FASN expression has been shown to be associated with the poor survival of patients, and with less sensitivity to gemcitabine in cell lines via the induction of ER stress that results in apoptosis. Another example of the lipid-mediated regulation of drug resistance is sphingomyelinase, an essential component of the cell membrane. Decitabine treatment may increase sphingomyelinase activity, thus leading to decreased sphingomyelin levels, which affects lipid composition and membrane fluidity (135). Such alterations in doxorubicin-resistant cells eventually facilitate drug transport and enhance drug efficacy. The function of membrane fluidity based on lipid profile, which ultimately affects anticancer drug transport and drug resistance, has also been studied (136). However, the influence of lipid profiles on cancer drug resistance requires further study.

In conclusion, although not conclusive, dysregulated cholesterol metabolism appears to be an essential contributing factor in the acquisition of drug resistance in several types of cancer. Therefore, preclinical models are required to confirm the regulation of cholesterol metabolism in cancer resistance, and preclinical results translating into useful practices in the clinic may provide an additional therapeutic approach to slow the progression of tumors.

\section{Acknowledgements}

Not applicable.

\section{Funding}

No funding was received.

\section{Availability of data and materials}

Not applicable.

\section{Authors' contributions}

AY contributed the general conception of the study and wrote the initial draft of the manuscript. ZJ was involved in the conception and design of the study, and revised the manuscript. CQ, MW and XD assisted in the literature search and revised the manuscript. All authors read and approved the final manuscript.

\section{Ethics approval and consent to participate}

Not applicable.

\section{Patient consent for publication}

Not applicable.

\section{Competing interests}

The authors declare that they have no competing interests.

\section{References}

1. Global Burden of Disease Cancer Collaboration; Fitzmaurice C, Abate D, Abbasi N, Abbastabar H,Abd-Allah F, Abdel-Rahman O, Abdelalim A, Abdoli A, Abdollahpour I, et al: Global, regional, and national cancer incidence, mortality, years of life lost, years lived with disability, and disability-adjusted life-years for 29 cancer groups, 1990 to 2017: A systematic analysis for the global burden of disease study. JAMA Oncol 5: 1749-1768, 2019.

2. Fojo A, Hamilton TC, Young RC and Ozols RF: Multidrug resistance in ovarian cancer. Cancer 60: 2075-2080, 1987.

3. Yang F, Gao B, Li R, Li W, Chen W, Yu Z and Zhang J: Expression levels of resistant genes affect cervical cancer prognosis. Mol Med Rep 15: 2802-2806, 2017.

4. Chun SY, Kwon YS, Nam KS and Kim S: Lapatinib enhances the cytotoxic effects of doxorubicin in MCF-7 tumorspheres by inhibiting the drug efflux function of $\mathrm{ABC}$ transporters. Biomed Pharmacother 72: 37-43, 2015.

5. International Transporter Consortium; Giacomini KM, Huang SM, Tweedie DJ, Benet LZ, Brouwer KL, Chu X, Dahlin A, Evers R, Fischer V, et al: Membrane transporters in drug development. Nat Rev Drug Discov 9: 215-236, 2010.

6. Longley DB and Johnston PG: Molecular mechanisms of drug resistance. J Pathol 205: 275-292, 2005.

7. Bedi A, Barber JP, Bedi GC, el-Deiry WS, Sidransky D, Vala MS, Akhtar AJ, Hilton J and Jones RJ: BCR-ABL-mediated inhibition of apoptosis with delay of G2/M transition after DNA damage: A mechanism of resistance to multiple anticancer agents. Blood 86: 1148-1158, 1995

8. Camidge DR, Pao W and Sequist LV: Acquired resistance to TKIs in solid tumours: Learning from lung cancer. Nat Rev Clin Oncol 11: 473-481, 2014.

9. Maier S, Dahlstroem C, Haefliger C, Plum A and Piepenbrock C: Identifying DNA methylation biomarkers of cancer drug response. Am J Pharmacogenomics 5: 223-232, 2005.

10. Taylor ST, Hickman JA and Dive C: Epigenetic determinants of resistance to etoposide regulation of $\mathrm{Bcl}-\mathrm{X}(\mathrm{L})$ and $\mathrm{Bax}$ by tumor microenvironmental factors. J Natl Cancer Inst 92: 18-23, 2000.

11. Maxfield FR and Tabas I: Role of cholesterol and lipid organization in disease. Nature 438: 612-621, 2005.

12. Gabitova L, Gorin A and Astsaturov I: Molecular pathways: Sterols and receptor signaling in cancer. Clin Cancer Res 20: 28-34, 2014

13. Zhang P, Wang D, Zhao Y, Ren S, Gao K, Ye Z, Wang S, Pan CW, Zhu Y, Yan Y, et al: Intrinsic BET inhibitor resistance in SPOP-mutated prostate cancer is mediated by BET protein stabilization and AKT-mTORC1 activation. Nat Med 23: 1055-1062, 2017. 
14. Wu Y, Si R, Tang H, He Z, Zhu H, Wang L, Fan Y, Xia S, He Z and Wang Q: Cholesterol reduces the sensitivity to platinum-based chemotherapy via upregulating ABCG2 in lung adenocarcinoma. Biochem Biophyes Res Commun 457: 614-620, 2015.

15. Sperling CD, Verdoodt F, Hansen MK, Dehlendorff C, Friis S and Kjaer SK: Statin use and mortality among endometrial cancer patients: A danish nationwide cohort study. Int J Cancer 143: 2668-2676, 2018.

16. Murtola TJ, Peltomaa AI, Talala K, Määttänen L, Taari K, Tammela TL and Auvinen A: Statin use and prostate cancer survival in the finnish randomized study of screening for prostate cancer. Eur Urol Focus 3: 212-220, 2017.

17. Rezen T, Rozman D, Pascussi JM and Monostory K: Interplay between cholesterol and drug metabolism. Biochim Biophys Acta 1814: 146-160, 2011

18. Cerqueira NM, Oliveira EF, Gesto DS, Santos-Martins D, Moreira C, Moorthy HN, Ramos MJ and Fernandes PA: Cholesterol biosynthesis: A mechanistic overview. Biochemistry 55: 5483-5506, 2016.

19. Bloch K: Summing up. Ann Rev Biochem 56: 1-19, 1987.

20. Goldstein JL and Brown MS: Regulation of the mevalonate pathway. Nature 343: 425-430, 1990.

21. Williamson IP and Kekwick RG: The formation of 5-phosphomevalonate by mevalonate kinase in hevea brasiliensis latex. Biochem J 96: 862-871, 1965.

22. Ačimovič J and Rozman D: Steroidal triterpenes of cholesterol synthesis. Molecules 18: 4002-4017, 2013.

23. Brown MS and Goldstein JL: Multivalent feedback regulation of HMG CoA reductase, a control mechanism coordinating isoprenoid synthesis and cell growth. J Lipid Res 21: 505-517, 1980.

24. Gilardi F, Mitro N, Godio C, Scotti E, Caruso D, Crestani M and De Fabiani E: The pharmacological exploitation of cholesterol 7alpha-hydroxylase, the key enzyme in bile acid synthesis: From binding resins to chromatin remodelling to reduce plasma cholesterol. Pharmacol Ther 116: 449-472, 2007.

25. Sakakura Y, Shimano H, Sone H, Takahashi A, Inoue N, Toyoshima H, Suzuki S and Yamada N: Sterol regulatory element-binding proteins induce an entire pathway of cholesterol synthesis. Biochem Biophys Res Commun 286: 176-183, 2001.

26. Montero J, Morales A, Llacuna L, Lluis JM, Terrones O, Basañez G, Antonsson B, Prieto J, García-Ruiz C, Colell A, et al: Mitochondrial cholesterol contributes to chemotherapy resistance in hepatocellular carcinoma. Cancer Res 68: 5246-5256, 2008.

27. Weber P, Wagner M and Schneckenburger H: Cholesterol dependent uptake and interaction of doxorubicin in MCF-7 breast cancer cells. Int J Mol Sci 14: 8358-8366, 2013.

28. Chen QF, Pan ZZ, Zhao M, Wang Q, Qiao C, Miao L and Ding X: High cholesterol in lipid rafts reduces the sensitivity to EGFR-TKI therapy in non-small cell lung cancer. J Cell Physiol 233: 6722-6732, 2018.

29. Yun UJ, Lee JH, Shim J, Yoon K, Goh SH, Yi EH, Ye SK, Lee JS, Lee H, Park J, et al: Anti-Cancer effect of doxorubicin is mediated by downregulation of HMG-Co A reductase via inhibition of EGFR/Src pathway. Lab Invest 99: 1157-1172, 2019.

30. Greife A, Tukova J, Steinhoff C, Scott SD, Schulz WA and Hatina J: Establishment and characterization of a bladder cancer cell line with enhanced doxorubicin resistance by mevalonate pathway activation. Tumor Biol 36: 3293-3300, 2015.

31. Kong YF, Cheng LJ, Mao FY, Zhang ZZ, Zhang YQ, Farah E, Bosler J, Bai YF, Ahmad N, Kuang S, et al: Inhibition of cholesterol biosynthesis overcomes enzalutamide resistance in castration-resistant prostate cancer (CRPC). J Biol Chem 293: 14328-14341, 2018

32. Kim YN, Jin H, He Y, Zhao P, Hu Y, Tao J, Chen J and Huang Y: Targeting lipid metabolism to overcome EMT-associated drug resistance via integrin $\beta 3 /$ FAK pathway and tumor-associated macrophage repolarization using legumain-activatable delivery. Theranostics 9: 265-278, 2019.

33. Gupta VK, Sharma NS, Kesh K, Dauer P, Nomura A, Giri B, Dudeja V, Banerjee S, Bhattacharya S, Saluja A and Banerjee S: Metastasis and chemoresistance in CD133 expressing pancreatic cancer cells are dependent on their lipid raft integrity. Cancer Lett 439: 101-112, 2018.

34. Glodkowska-Mrowka E, Mrowka P, Basak GW Niesiobedzka-Krezel J, Seferynska I, Wlodarski PK, Jakobisiak M and Stoklosa T: Statins inhibit ABCB1 and ABCG2 drug transporter activity in chronic myeloid leukemia cells and potentiate antileukemic effects of imatinib. Exp Hematol 42: 439-447, 2014
35. Chen Y, Liu G, Guo L, Wang H, Fu Y and Luo Y: Enhancement of tumor uptake and therapeutic efficacy of EGFR-targeted antibody cetuximab and antibody-drug conjugates by cholesterol sequestration. Int J Cancer 136: 182-194, 2015.

36. Chen X, Liu Y, Wu J, Huang HR, Du ZY, Zhang K, Zhou DY, Hung K, Goodin S and Zheng X: Mechanistic study of inhibitory effects of atorvastatin and docetaxel in combination on prostate cancer. Cancer Genomics Proteomics 13: 151-160, 2016.

37. Brown MS and Goldstein JL: Receptor-Mediated control of cholesterol metabolism. Science 191: 150-154, 1976.

38. Brown MS and Goldstein JL: A receptor-mediated pathway for cholesterol homeostasis. Science 232: 34-47, 1986.

39. Acton S, Rigotti A, Landschulz KT, Xu S, Hobbs HH and Krieger M: Identification of scavenger receptor SR-BI as a high density lipoprotein receptor. Science 271: 518-520, 1996.

40. Landschulz KT, Pathak RK, Rigotti A, Krieger M and Hobbs HH: Regulation of scavenger receptor, class B, type I, a high density lipoprotein receptor, in liver and steroidogenic tissues of the rat. J Clin Invest 98: 984-995, 1996.

41. Betters JL and Yu L: NPC1L1 and cholesterol transport. FEBS Lett 584: 2740-2747, 2010.

42. Rader DJ, Alexander ET, Weibel GL, Billheimer J and Rothblat GH: The role of reverse cholesterol transport in animals and humans and relationship to atherosclerosis. J Lipid Res 50 (Suppl): S189-S194, 2009.

43. Maranghi M, Truglio G, Gallo A, Grieco E, Verrienti A Montali A, Gallo P, Alesini F, Arca M and Lucarelli M: A novel splicing mutation in the ABCA1 gene, causing tangier disease and familial HDL deficiency in a large family. Biochem Biophys Res Commun 508: 487-493, 2019.

44. Vedhachalam C, Duong PT, Nickel M, Nguyen D, Dhanasekaran P, Saito H, Rothblat GH, Lund-Katz S and Phillips MC: Mechanism of ATP-binding cassette transporter A1-mediated cellular lipid efflux to apolipoprotein A-I and formation of high density lipoprotein particles. J Biol Chem 282: 25123-25130, 2007.

45. Gelissen IC, Harris M, Rye KA, Quinn C, Brown AJ, Kockx M, Cartland S, Packianathan M, Kritharides L and Jessup W: ABCA1 and ABCG1 synergize to mediate cholesterol export to apoA-I. Arterioscler Thromb Vasc Biol 26: 534-540, 2006.

46. Jessup W, Gelissen IC, Gaus K and Kritharides L: Roles of ATP binding cassette transporters A1 and G1, scavenger receptor BI and membrane lipid domains in cholesterol export from macrophages. Curr Opin Lipidol 17: 247-257, 2006.

47. Wang J, Mitsche MA, Lutjohann D, Cohen JC, Xie XS and Hobbs HH: Relative roles of ABCG5/ABCG8 in liver and intestine. J Lipid Res 56: 319-330, 2015.

48. Connelly MA and Williams DL: Scavenger receptor BI: A scavenger receptor with a mission to transport high density lipoprotein lipids. Curr Opin Lipidol 15: 287-295, 2004.

49. Huang ZH, Gu D, Lange Y and Mazzone T: Expression of scavenger receptor $\mathrm{BI}$ facilitates sterol movement between the plasma membrane and the endoplasmic reticulum in macrophages. Biochemistry 42: 3949-3955, 2003.

50. Calkin AC and Tontonoz P: Transcriptional integration of metabolism by the nuclear sterol-activated receptors LXR and FXR. Nat Rev Mol Cell Biol 13: 213-224, 2012.

51. Goldstein JL, DeBose-Boyd RA and Brown MS: Protein sensors for membrane sterols. Cell 124: 35-46, 2006.

52. Brown MS and Goldstein JL: The SREBP pathway: Regulation of cholesterol metabolism by proteolysis of a membrane-bound transcription factor. Cell 89: 331-340, 1997.

53. Shimano H: SREBPs: Physiology and pathophysiology of the SREBP family. FEBS J 276: 616-621, 2009

54. Radhakrishnan A, Goldstein JL, McDonald JG and Brown MS: Switch-Like control of SREBP-2 transport triggered by small changes in ER cholesterol: A delicate balance. Cell Metab 8: 512-521, 2008.

55. Lo Sasso G, Murzilli S, Salvatore L, D'Errico I, Petruzzelli M, Conca P, Jiang ZY, Calabresi L, Parini P and Moschetta A: Intestinal specific LXR activation stimulates reverse cholesterol transport and protects from atherosclerosis. Cell Metab 12: 187-193, 2010.

56. Duval C, Touche V, Tailleux A, Fruchart JC, Fievet C, Clavey V, Staels B and Lestavel S: Niemann-Pick C1 like 1 gene expression is down-regulated by LXR activators in the intestine. Biochem Biophys Res Commun 340: 1259-1263, 2006.

57. Cancer Genome Atlas Research Network; Weinstein JN, Collisson EA, Mills GB, Shaw KR, Ozenberger BA, Ellrott K, Shmulevich I, Sander C and Stuart JM: The cancer genome atlas pan-cancer analysis project. Nat Genet 45: 1113-1120, 2013 
58. Kuzu OF, Noory MA and Robertson GP: The role of cholesterol in cancer. Cancer Res 76: 2063-2070, 2016.

59. Li JJ, Qu XC, Tian J, Zhang JT and Cheng JX: Cholesterol esterification inhibition and gemcitabine synergistically suppress pancreatic ductal adenocarcinoma proliferation. PLoS One 13: e0193318, 2018.

60. Hultsch S, Kankainen M, Paavolainen L, Kovanen RM, Ikonen E, Kangaspeska S, Pietiäinen V and Kallioniemi O: Association of tamoxifen resistance and lipid reprogramming in breast cancer. BMC Cancer 18: 850, 2018.

61. May GL, Wright LC, Dyne M, Mackinnon WB, Fox RM and Mountford CE: Plasma membrane lipid composition of vinblastine sensitive and resistant human leukaemic lymphoblasts. Int J Cancer 42: 728-733, 1988.

62. Nguyen VT, Barozzi I, Faronato M, Lombardo Y, Steel JH, Patel N, Darbre P, Castellano L, Győrffy B, Woodley L, et al: Differential epigenetic reprogramming in response to specific endocrine therapies promotes cholesterol biosynthesis and cellular invasion. Nat Commun 6: 10044, 2015.

63. Souchek JJ, Baine MJ, Lin C, Rachagani S, Gupta S, Kaur S, Lester K, Zheng D, Chen S, Smith L, et al: Unbiased analysis of pancreatic cancer radiation resistance reveals cholesterol biosynthesis as a novel target for radiosensitisation. Br J Cancer 111: $1139-1149,2014$

64. Bandyopadhyay S, Li J, Traer E, Tyner JW, Zhou A, Oh ST and Cheng JX: Cholesterol esterification inhibition and imatinib treatment synergistically inhibit growth of BCR-ABL mutation-independent resistant chronic myelogenous leukemia. PLoS One 12: e0179558, 2017.

65. Dominguez-Perez M, Simoni-Nieves A, Rosales $P$ Nuño-Lámbarri N, Rosas-Lemus M, Souza V, Miranda RU, Bucio L, Carvajal SU, Marquardt JU, et al: Cholesterol burden in the liver induces mitochondrial dynamic changes and resistance to apoptosis. J Cell Physiol 234: 7213-7223, 2019.

66. Smith B and Land H: Anticancer activity of the cholesterol exporter ABCA1 gene. Cell Rep 2: 580-590, 2012.

67. Crain RC, Clark RW and Harvey BE: Role of lipid transfer proteins in the abnormal lipid content of morris hepatoma mitochondria and microsomes. Cancer Res 43: 3197-3202, 1983.

68. Yamamoto $\mathrm{Y}$, Tomiyama A, Sasaki N, Yamaguchi $\mathrm{H}$, Shirakihara T, Nakashima T, Kumagai K, Takeuchi S, Toyooka T, Otani N, et al: Intracellular cholesterol level regulates sensitivity of glioblastoma cells against temozolomide-induced cell death by modulation of caspase- 8 activation via death receptor 5-accumulation and activation in the plasma membrane lipid raft. Biochem Biophys Res Commun 495 1292-1299, 2018.

69. Ikonen E: Cellular cholesterol trafficking and compartmentalization. Nat Rev Mol Cell Biol 9: 125-138, 2008

70. Pike LJ: Lipid rafts: Heterogeneity on the high seas. Biochem J 378: 281-292, 2004

71. Li YC, Park MJ, Ye SK, Kim CW and Kim YN: Elevated levels of cholesterol-rich lipid rafts in cancer cells are correlated with apoptosis sensitivity induced by cholesterol-depleting agents. Am J Pathol 168: 1107-1118, 2006

72. Vieira AV, Lamaze C and Schmid SL: Control of EGF receptor signaling by clathrin-mediated endocytosis. Science 274 2086-2089, 1996.

73. Sigismund S, Argenzio E, Tosoni D, Cavallaro E, Polo S and Di Fiore PP: Clathrin-Mediated internalization is essential for sustained EGFR signaling but dispensable for degradation. Dev Cell 15: 209-219, 2008

74. Jiang S, Wang X, Song D, Liu X, Gu Y, Xu Z, Wang X, Zhang X, Ye Q, Tong Z, et al: Cholesterol induces epithelial-to-mesenchymal transition of prostate cancer cells by suppressing degradation of EGFR through APMAP. Cancer Res 15: 3063-3075, 2019.

75. Su YJ, Lin WH, Chang YW, Wei KC, Liang CL, Chen SC and Lee JL: Polarized cell migration induces cancer type-specific CD133/integrin/Src/Akt/GSK3 beta/beta-catenin signaling required for maintenance of cancer stem cell properties Oncotarget 6: 38029-38045, 2015.

76. Prieto-Vila M, Takahashi RU, Usuba W, Kohama I and Ochiya T: Drug resistance driven by cancer stem cells and their niche. Int J Mol Sci 18: 2574, 2017

77. Drab M, Verkade P, Elger M, Kasper M, Lohn M, Lauterbach B, Menne J, Lindschau C, Mende F, Luft FC, et al: Loss of caveolae, vascular dysfunction, and pulmonary defects in caveolin-1 gene-disrupted mice. Science 293: 2449-2452, 2001.
78. Chatterjee M, Ben-Josef E, Thomas DG, Morgan MA, Zalupski MM, Khan G, Andrew Robinson C, Griffith KA, Chen CS, Ludwig T, et al: Caveolin-1 is associated with tumor progression and confers a multi-modality resistance phenotype in pancreatic cancer. Sci Rep 5: 10867, 2015.

79. Li Z, Wang N, Huang C, Bao Y, Jiang Y and Zhu G: Downregulation of caveolin-1 increases the sensitivity of drug-resistant colorectal cancer HCT116 cells to 5-fluorouracil. Oncol Lett 13: 483-487, 2017.

80. Karantanos T, Karanika S, Wang J, Yang G, Dobashi M, Park S, Ren C, Li L, Basourakos SP, Hoang A, et al: Caveolin-1 regulates hormone resistance through lipid synthesis, creating novel therapeutic opportunities for castration-resistant prostate cancer. Oncotarget 7: 46321-46334, 2016.

81. Mohammad N, Malvi P, Meena AS, Singh SV, Chaube B Vannuruswamy G, Kulkarni MJ and Bhat MK: Cholesterol depletion by methyl-beta-cyclodextrin augments tamoxifen induced cell death by enhancing its uptake in melanoma. Mol Cancer 13: 204, 2014.

82. Troost J, Albermann N, Haefeli WE and Weiss J: Cholesterol modulates P-glycoprotein activity in human peripheral blood mononuclear cells. Biochem Biophys Res Commun 316: 705-711, 2004.

83. Rothnie A, Theron D, Soceneantu L, Martin C, Traikia M, Berridge G, Higgins CF, Devaux PF and Callaghan R: The importance of cholesterol in maintenance of P-glycoprotein activity and its membrane perturbing influence. Eur Biophys J 30: 430-442, 2001.

84. Kamau SW, Krämer SD, Günthert M and Wunderli-Allenspach H: Effect of the modulation of the membrane lipid composition on the localization and function of P-glycoprotein in MDR1-MDCK cells. In Vitro Cell Dev Anim 41: 207-216, 2005.

85. Gayet L, Dayan G, Barakat S, Labialle S, Michaud M, Cogne S, Mazane A, Coleman AW, Rigal D and Baggetto LG: Control of P-glycoprotein activity by membrane cholesterol amounts and their relation to multidrug resistance in human CEM leukemia cells. Biochemistry 44: 4499-4509, 2005.

86. Eckford PD and Sharom FJ: Interaction of the P-glycoprotein multidrug efflux pump with cholesterol: Effects on ATPase activity, drug binding and transport. Biochemistry 47: 13686-13698, 2008.

87. Subramanian N, Schumann-Gillett A, Mark AE and O'Mara ML: Understanding the accumulation of P-glycoprotein substrates within cells: The effect of cholesterol on membrane partitioning. Biochim Biophys Acta 1858: 776-782, 2016.

88. Gelsomino G, Corsetto PA, Campia I, Montorfano G, Kopecka J, Castella B, Gazzano E, Ghigo D, Rizzo AM and Riganti C: Omega 3 fatty acids chemosensitize multidrug resistant colon cancer cells by down-regulating cholesterol synthesis and altering detergent resistant membranes composition. Mol Cancer 12: 137, 2013.

89. Chen W, Zhang YW, Li Y, Zhang JW, Zhang T, Fu BS, Zhang Q and Jiang N: Constitutive expression of wnt/betacatenin target genes promotes proliferation and invasion of liver cancer stem cells. Mol Med Rep 13: 3466-3474, 2016.

90. Pál A, Méhn D, Molnár E, Gedey S, Mészáros P, Nagy T, Glavinas H, Janáky T, von Richter O, Báthori G, et al: Cholesterol potentiates $\mathrm{ABCG} 2$ activity in a heterologous expression system: Improved in vitro model to study function of human ABCG2. J Pharmacol Exp Ther 321: 1085-1094, 2007.

91. Telbisz A, Müller M, Ozvegy-Laczka C, Homolya L, Szente L, Váradi A and Sarkadi B: Membrane cholesterol selectively modulates the activity of the human ABCG2 multidrug transporter. Biochem Biophys Acta 1768: 2698-2713, 2007.

92. Takano M, Higashi M, Ito H, Toyota S, Hirabayashi $\mathrm{Y}$ and Yumoto R: Functional expression of breast cancer resistance protein and cholesterol effect in human erythrocyte membranes. Pharmazie 73: 700-705, 2018

93. Marbeuf-Gueye C, Stierle V, Sudwan P, Salerno M and Garnier-Suillerot A: Perturbation of membrane microdomains in GLC4 multidrug-resistant lung cancer cells-modification of ABCC1 (MRP1) localization and functionality. FEBS J 274: 1470-1480, 2007

94. Pallarés-Trujillo J, Domènech $\mathrm{C}$, Grau-Oliete MR and Rivera-Fillat MP: Role of cell cholesterol in modulating vincristine uptake and resistance. Int J Cancer 55: 667-671, 1993.

95. Rivel T, Ramseyer C and Yesylevskyy S: The asymmetry of plasma membranes and their cholesterol content influence the uptake of cisplatin. Sci Rep 9: 5627, 2019.

96. Sharma B, Gupta V, Dahiya D, Kumar H, Vaiphei K and Agnihotri N: Clinical relevance of cholesterol homeostasis genes in colorectal cancer. Biochim Biophys Acta Mol Cell Biol Lipids 1864: 1314-1327, 2019. 
97. Simigdala N, Gao Q, Pancholi S, Roberg-Larsen H, Zvelebil M, Ribas R, Folkerd E, Thompson A, Bhamra A, Dowsett M and Martin LA: Cholesterol biosynthesis pathway as a novel mechanism of resistance to estrogen deprivation in estrogen receptor-positive breast cancer. Breast Cancer Res 18: 58, 2016.

98. Kimbung S, Lettiero B, Feldt M, Bosch A and Borgquist S: High expression of cholesterol biosynthesis genes is associated with resistance to statin treatment and inferior survival in breast cancer. Oncotarget 7: 59640-59651, 2016.

99. Kim S, Lee M, Dhanasekaran DN and Song YS: Activation of $\mathrm{LXRa}$ /beta by cholesterol in malignant ascites promotes chemoresistance in ovarian cancer. BMC Cancer 18: 1232, 2018.

100. Zhou P, Li B, Liu B, Chen T and Xiao J: Prognostic role of serum total cholesterol and high-density lipoprotein cholesterol in cancer survivors: A systematic review and meta-analysis. Clin Chim Acta 477: 94-104, 2018.

101. Rodrigues Dos Santos C, Fonseca I, Dias S and de Almeida JC: Plasma level of LDL-cholesterol at diagnosis is a predictor factor of breast tumor progression. BMC Cancer 14: 132, 2014.

102. Lofterød T, Mortensen ES, Nalwoga H, Wilsgaard T, Frydenberg H, Risberg T, Eggen AE, McTiernan A, Aziz S, Wist EA, et al: Impact of pre-diagnostic triglycerides and HDL-cholesterol on breast cancer recurrence and survival by breast cancer subtypes. BMC Cancer 18: 654, 2018.

103. Wulaningsih W, Vahdaninia M, Rowley M, Holmberg L, Garmo H, Malmstrom H, Lambe M, Hammar N, Walldius G, Jungner I, et al: Prediagnostic serum glucose and lipids in relation to survival in breast cancer patients: A competing risk analysis. BMC Cancer 15: 913, 2015.

104. Tamura T, Inagawa S, Hisakura K, Enomoto T and Ohkohchi N: Evaluation of serum high-density lipoprotein cholesterol levels as a prognostic factor in gastric cancer patients. J Gastroentero Hepatol 27: 1635-1640, 2012.

105. Que Y, Jiang F, Liu L, Li Y, Chen Y, Qiu H, Zhou Z and Zhang X: Clinical significance of preoperative serum high density lipoprotein cholesterol levels in soft tissue sarcoma. Medicine (Baltimore) 94: e844, 2015

106. Wei LJ, Zhang C, Zhang H, Wei X, Li SX, Liu JT and Ren XB: A case-control study on the association between serum lipid level and the risk of breast cancer. Zhonghua Yu Fang Yi Xue Za Zhi 50: 1091-1095, 2016 (In Chinese)

107. Cambien F, Ducimetiere P and Richard J: Total serum cholesterol and cancer mortality in a middle-aged male population. Am J Epidemiol 112: 388-394, 1980.

108. Sherwin RW, Wentworth DN, Cutler JA, Hulley SB, Kuller LH and Stamler J: Serum cholesterol levels and cancer mortality in 361,662 men screened for the multiple risk factor intervention trial. JAMA 257: 943-948, 1987.

109. Kim TH, Ahn SJ, Jung WT, Lee OJ, Ha WS and Jang JS: Clinical significance of the levels of serum cholesterol in patients with gastric cancer. Cancer Res Treat 35: 335-340, 2003.

110. Ohno Y, Nakashima J, Nakagami Y, Gondo T, Ohori M, Hatano $\mathrm{T}$ and Tachibana M: Clinical implications of preoperative serum total cholesterol in patients with clear cell renal cell carcinoma. Urology 83: 154-158, 2014.

111. Sok M, Ravnik J and Ravnik M: Preoperative total serum cholesterol as a prognostic factor for survival in patients with resectable non-small-cell lung cancer. Wien Klin Wochenschr 121: 314-317, 2009.

112. Larsen SB, Dehlendorff C, Skriver C, Dalton SQ, Jespersen CG, Borre M, Brasso K, Nørgaard M, Johansen C, Sørensen HT, et al: Postdiagnosis statin use and mortality in danish patients with prostate cancer. J Clin Oncol 35: 3290-3297, 2017.

113. Liu B, Yi Z, Guan X, Zeng YX and Ma F: The relationship between statins and breast cancer prognosis varies by statin type and exposure time: A meta-analysis. Breast Cancer Res Treat 164: 1-11, 2017

114. Kim HY, Kim DK, Bae SH, Gwak H, Jeon JH, Kim JK, Lee BI, You HJ, Shin DH, Kim YH, et al: Farnesyl diphosphate synthase is important for the maintenance of glioblastoma stemness. Exp Mol Med 50: 1-12, 2018.

115. Ginestier C, Monville F, Wicinski J, Cabaud O, Cervera N, Josselin E, Finetti P, Guille A, Larderet G, Viens P, et al: Mevalonate metabolism regulates Basal breast cancer stem cells and is a potential therapeutic target. Stem Cells 30: 1327-1337, 2012.

116. Yang CM, Lu YL, Chen HY and Hu ML: Lycopene and the LXRalpha agonist T0901317 synergistically inhibit the proliferation of androgen-independent prostate cancer cells via the PPAR $\gamma$-LXR $\alpha$-ABCA1 pathway. J Nutr Biochem 23: 1155-1162, 2012.
117. EL Roz A, Bard JM, Huvelin JM and Nazih H: LXR agonists and ABCG1-dependent cholesterol efflux in MCF-7 breast cancer cells: Relation to proliferation and apoptosis. Anticancer Res 32: 3007-3013, 2012

118. El Roz A, Bard JM, Huvelin JM and Nazih H: The anti-proliferative and pro-apoptotic effects of the trans9, trans11 conjugated linoleic acid isomer on MCF-7 breast cancer cells are associated with LXR activation. Prostaglandins Leukot Essent Fatty Acids 88: 265-272, 2013.

119. Zhang L, Jiang M, Shui Y, Chen Y, Wang Q, Hu W, Ma X, Li X, Liu X, Cao X, et al: DNA topoisomerase II inhibitors induce macrophage ABCA1 expression and cholesterol efflux-an LXR-dependent mechanism. Biochim Biophys Acta 1831: 1134-1145, 2013.

120. Naren D, Wu J, Gong Y, Yan T, Wang K, Xu W, Yang X, Shi F and Shi R: Niemann-Pick disease type Cl(NPC1) is involved in resistance against imatinib in the imatinib-resistant $\mathrm{Ph}+$ acute lymphoblastic leukemia cell line SUP-B15/RI. Leuk Res 42: 59-67, 2016.

121. Kuzu OF, Gowda R, Sharma A and Robertson GP: Leelamine mediates cancer cell death through inhibition of intracellular cholesterol transport. Mol Cancer Ther 13: 1690-1703, 2014.

122. Gowda R, Inamdar GS, Kuzu O, Dinavahi SS, Krzeminski J, Battu MB, Voleti SR, Amin S and Robertson GP: Identifying the structure-activity relationship of leelamine necessary for inhibiting intracellular cholesterol transport. Oncotarget 8: 28260-28277, 2017.

123. Rios-Marco P, Martín-Fernández M, Soria-Bretones I, Ríos A, Carrasco MP and Marco C: Alkylphospholipids deregulate cholesterol metabolism and induce cell-cycle arrest and autophagy in U-87 MG glioblastoma cells. Biochim Biophys Acta 1831: 1322-1334, 2013.

124. Liu R, Li J, Zhang T, Zou L, Chen Y, Wang K, Lei Y, Yuan K, $\mathrm{Li}$ Y, Lan J, et al: Itraconazole suppresses the growth of glioblastoma through induction of autophagy: Involvement of abnormal cholesterol trafficking. Autophagy 10: 1241-1255, 2014.

125. Kuzu OF, Gowda R, Noory MA and Robertson GP: Modulating cancer cell survival by targeting intracellular cholesterol transport. Br J Cancer 117: 513-524, 2017.

126. PeltonK,CoticchiaCM,Curatolo AS,SchaffnerCP,ZurakowskiD, Solomon KR and Moses MA: Hypercholesterolemia induces angiogenesis and accelerates growth of breast tumors in vivo. Am J Pathol 184: 2099-2110, 2014.

127. Lin X, Liu L, Fu Y, Gao J, He Y, Wu Y and Lian X: Dietary cholesterol intake and risk of lung cancer: A meta-analysis. Nutrients 10: 185, 2018

128. Li C, Yang L, Zhang D and Jiang W: Systematic review and meta-analysis suggest that dietary cholesterol intake increases risk of breast cancer. Nutr Res 36: 627-635, 2016.

129. Hu J, La Vecchia C, de Groh M, Negri E, Morrison H and Mery L; Canadian Cancer Registries Epidemiology Research Group: Dietary cholesterol intake and cancer. Ann Oncol 23: 491-500, 2012

130. Genkinger JM, Hunter DJ, Spiegelman D, Anderson KE, Beeson WL, Buring JE, Colditz GA, Fraser GE, Freudenheim JL, Goldbohm RA, et al: A pooled analysis of 12 cohort studies of dietary fat, cholesterol and egg intake and ovarian cancer. Cancer Causes Control 17: 273-285, 2006

131. Solomon KR, Pelton K, Boucher K, Joo J, Tully C, Zurakowski D, Schaffner CP, Kim J and Freeman MR: Ezetimibe is an inhibitor of tumor angiogenesis. Am J Pathol 174: 1017-1026, 2009.

132. Xu X, Han K, Zhu J, Mao H, Lin X, Zhang Z, Cao B, Zeng Y and Mao X: An inhibitor of cholesterol absorption displays anti-myeloma activity by targeting the JAK2-STAT3 signaling pathway. Oncotarget 7: 75539-75550, 2016.

133. Menendez JA, Vellon L and Lupu R: Targeting fatty acid synthase-driven lipid rafts: A novel strategy to overcome trastuzumab resistance in breast cancer cells. Med Hypotheses 64: 997-1001, 2005.

134. Tadros S, Shukla SK, King RJ, Gunda V, Vernucci E, Abrego J, Chaika NV, Yu F, Lazenby AJ, Berim L, et al: De novo lipid synthesis facilitates gemcitabine resistance through endoplasmic reticulum stress in pancreatic cancer. Cancer Res 77: 5503-5517, 2017

135. Vijayaraghavalu S, Peetla C, Lu S and Labhasetwar V: Epigenetic modulation of the biophysical properties of drug-resistant cel lipids to restore drug transport and endocytic functions. Mol Pharm 9: 2730-2742, 2012.

136. Todor IN, Lukyanova NY and Chekhun VF: The lipid content of cisplatin- and doxorubicin-resistant MCF-7 human breast cancer cells. Exp Oncol 34: 97-100, 2012. 